\title{
Silent strain of caregiving: exploring the best predictors of distress in family carers of geriatric patients
}

\author{
Katarzyna Bień-Barkowska' \\ Halina Doroszkiewicz ${ }^{2}$ \\ Barbara Bień \\ 'Institute of Econometrics, Warsaw \\ School of Economics, Warsaw, \\ ${ }^{2}$ Department of Geriatrics, Medical \\ University of Białystok, Białystok, \\ Poland
}

This article was published in the following Dove Press journal:

Clinical Interventions in Aging

2 February 2017

Number of times this article has been viewed

Objectives: The aim of this article was to identify the best predictors of distress suffered by family carers (FCs) of geriatric patients.

Methods: A cross-sectional study of 100 FC-geriatric patient dyads was conducted. The negative impact of care (NIoC) subscale of the COPE index was dichotomized to identify lower stress (score of $\leq 15$ on the scale) and higher stress (score of $\geq 16$ on the scale) exerted on FCs by the process of providing care. The set of explanatory variables comprised a wide range of sociodemographic and care-related attributes, including patient-related results from comprehensive geriatric assessments and disease profiles. The best combination of explanatory variables that provided the highest predictive power for distress among FCs in the multiple logistic regression (LR) model was determined according to statistical information criteria. The statistical robustness of the observed relationships and the discriminative power of the model were verified with the cross-validation method.

Results: The mean age of FCs was $57.2( \pm 10.6)$ years, whereas that of geriatric patients was 81.7 ( \pm 6.4 ) years. Despite the broad initial set of potential explanatory variables, only five predictors were jointly selected for the best statistical model. A higher level of distress was independently predicted by lower self-evaluation of health; worse self-appraisal of coping well as a caregiver; lower sense of general support; more hours of care per week; and the motor retardation of the cared-for person measured with the speed of the Timed Up and Go (TUG) test.

Conclusion: Worse performance on the TUG test was only the patient-related predictor of distress among the variables examined as contributors to the higher NIoC. Enhancing the mobility of geriatric patients through suitably tailored kinesitherapeutic methods during their hospital stay may mitigate the burden endured by FCs.

Keywords: negative impact of care, caregiver burden, comprehensive geriatric assessment, Timed Up and Go test

\section{Introduction}

A global upsurge in human life expectancy and the recent phenomenon of late-life mortality deceleration have contributed to a higher demand for long-term care. ${ }^{1,2}$ Accordingly, an increasing number of older people are living a longer life while struggling with comorbidities, physical and mental disabilities, emotional distress, and a rising level of dependency. ${ }^{3}$ Usually, they require family assistance or other informal and personal forms of care as well as supportive services from health and social care providers. ${ }^{4}$ However, most disabled older adults prefer to be supported by their close relatives at home. ${ }^{2}$

As the baby-boom generation ages, a family can be perceived as a fundamental "care institution," contributing to the success of policies aimed at keeping older
Correspondence: Katarzyna BieńBarkowska

Institute of Econometrics, Warsaw School of Economics, Madalińskiego 6/8, 02-510 Warsaw, Poland

Tel +48225649256

Fax +48 225648617

Email katarzyna.bien@sgh.waw.pl 
people safe in their own homes and communities. Family carers (FCs) have a plethora of diverse responsibilities: providing nursing and transportation services for seniors; satisfying their hygienic, therapeutic, and emotional needs; and giving them psychological support. ${ }^{5,6}$ Whether they are spouses, children, or more distant relatives, they are usually willing to broaden the range of care if required. ${ }^{7}$ However, the vast scope of duties fulfilled by FCs often overwhelms them, contributing to reductions in their employment or hours of work ${ }^{8,9}$ as well as deterioration of their physical and psychological health and, hence, a decrease in the wellbeing of all family members. ${ }^{10}$ These negative outcomes can escalate over time in parallel with the health deterioration of the cared-for persons. The negative impact of providing care is not recognized as a disease or a dysfunction, although sometimes it is compared to a "silent disease" or to "suffering in silence" 11 and is often overlooked by clinicians focused only on the health problems of their elderly patients.

It is widely recognized that providing care causes a multifaceted burden that encompasses the physical, psychological, and social spheres of a caregiver's life. ${ }^{12-14}$ The first tool for quantification of this multidimensional hardship was developed by Zarit et al in 1980; ${ }^{15}$ the Burden Interview was constructed to evaluate the stress levels experienced by carers of dementia ${ }^{16,17}$ and nondementia patients. ${ }^{18}$ Soon afterward, other instruments were proposed. However, they often demanded very laborious evaluation processes. ${ }^{6}$ The tool that we use in this study for assessing a caregiver's distress from providing care is a short, seven-item subscale of the COPE index developed by the Carers of Older People in Europe partnership. ${ }^{19}$ This tool is specially designed as a brief first-stage screening instrument, feasible for use in clinical practice and suitably tailored to identify the carers who may require supportive intervention. The COPE index emphasizes the subjective assessment by a caregiver of his or her own situation and circumstances. Thus, it partially shares the same conceptual territory as the burden of care but is intended to better capture how a caregiver self-evaluates on his or her individual internal scale, both cognitively and emotionally, in addition to the experiences and difficulties that he or she is going through in the process of providing care. Moreover, the COPE index discriminates between negative and positive aspects of providing care, as it comprises three subscales: "negative impact" that measures the stress associated with providing care, "positive value" that quantifies satisfaction gained from being a caregiver, and "quality of support" that assesses self-perceived assistance from family members, friends, neighbors, and health and social services.
The aforementioned three subscales reflect independent dimensions of care and have to be interpreted separately. They have also been validated as internally consistent, using a large sample of FCs drawn from six European countries. ${ }^{20}$

According to the literature, the range of risk factors for distress suffered by FCs may be extensive. The results of a recent meta-analysis ${ }^{11}$ point to the most significant risk factors being: female sex, low level of education, common residence with care recipients, depression and social isolation, financial stress, higher number of hours spent caregiving, and a lack of choice in being a caregiver. However, the substantial and chronic burden of an FC can be alleviated if clinicians allow FCs to act as proactive partners in care, recognize their burden, and intervene in order to reduce it. ${ }^{11}$ On the other hand, some studies also list care recipient-dependent or environment-dependent factors that result in a negative impact of care (NIoC), for example, patients' dyspnea, ${ }^{21}$ anemia, and poor mobility performance; ${ }^{22}$ behavioral disorders; ${ }^{23}$ the duration of care $;{ }^{24}$ or socioeconomic situation. ${ }^{25}$ However, studies that investigate the burden associated with providing care are usually selective in their setup, collecting data from patients with dementia, ${ }^{16,23-27}$ with other well-defined conditions such as cancer ${ }^{22,23,28}$ or Parkinson's disease, ${ }^{29}$ or are based on ambulatory or nursing home patients..$^{30,31}$ To this end, very little is still known about the key factors that aggravate the chronic stress endured by caregivers of geriatric inpatients, hence the "oldest, comorbid, most complicated and frail" medical cases suffering from many overlapping medical conditions. ${ }^{32}$ The purpose of this study is to identify and investigate the best predictors of the highly negative effects that providing care to a comorbid older person exerts on his or her FC. This analysis can also be helpful in identifying those FCs who intrinsically feel distressed and overwhelmed with the demands and challenges of providing care.

\section{Methods \\ Design and participants}

The data were collected from FCs and matched with the hospital records of the cared-for persons at their admission or during their short-term stay in a geriatric unit. Only community-dwelling inpatients with available FCs who agreed to participate in the study were involved. All FCs gave informed written consent, and this study was performed in adherence with the principles of the Declaration of Helsinki and approved by the Bioethics Committee of the Medical University (Resolution no. R-I-002/256/2013).

Altogether, 100 FC-inpatient dyads were recruited from June 2014 to September 2015. Our secondary care sample 
consisted of inpatients, usually of advanced old age and with complex morbidities, referred to the geriatric ward by general practitioners, most commonly due to the deterioration of their chronic conditions. FCs were interviewed following a questionnaire with structured response alternatives and a few open-ended questions. The 88-item questionnaire for FCs combined questions from both the EUROFAMCARE questionnaire $^{7}$ and the COPE survey. ${ }^{19}$ The interviews were conducted face-to-face without the presence of the cared-for persons.

The data for this study included inpatient interviews, laboratory reports, and clinical diagnoses, as well as various elements of the comprehensive geriatric assessment that provides the most complete interdisciplinary diagnostic instrument for the identification of medical problems in older patients. ${ }^{33}$

\section{Dependent variable}

The NIoC was measured using the seven-item negative impact subscale of the COPE index with a possible range of values from 7 (minimal burden) to 28 (maximal burden). ${ }^{19,20}$ According to Balducci et al, ${ }^{20}$ a caregiver who scores high on this subscale experiences high stress from providing care. The following questions were used to quantify the NIoC: 1) Is caregiving too demanding? 2) Does caregiving cause difficulties in your relationships with friends? 3) Does caregiving have a negative effect on your physical health? 4) Does caregiving cause difficulties in your relationship with your family? 5) Does caregiving cause you financial difficulties? 6) Do you feel trapped in your role as a caregiver? 7) Does caregiving have a negative effect on your emotional well-being? Each of these questions can be answered with "never" or "not applicable" (assigned value =1), "sometimes" (assigned value =2), "often" (assigned value =3), or "always" (assigned value $=4$ ). The NIoC was quantified as the sum of the numerical values assigned to all answer choices. The Cronbach's alpha measure of NIoC scale reliability was 0.75 .

The dependent variable was defined as a dichotomous indicator of stress experienced in the process of providing care, where lower stress corresponds to NIoC $\leq 15$ and higher stress to NIoC $>15$. The threshold value of NIoC $=15$ corresponds to the median value of the NIoC score in our sample that comprises FCs of geriatric patients only. At the same time, the cut point of NIoC $>15$ distinguishes the $20 \%$ of all FCs who are the most severely burdened (ie, those FCs who had the highest score on the "NIoC" subscale), according to the large cross-sectional EUROFAMCARE survey on 6,000 informal carers of older people recruited in six European countries in $2005 .^{20}$

\section{Predictors \\ Carers' data}

We included many sociodemographic and care-related characteristics reported by FCs as potential explanatory variables (ie, predictors) for higher stress associated with providing care (Table 1). These variables included: FC's age (in years), gender (male or female), marital status (married vs widowed, divorced, or single), place of residence (big city, small town, or village), employment (yes or no), relationship with the person in care (spouse, child, grandchild, sibling, or other relative), coresidence with older cared-for person (yes or no), education (primary, secondary, or higher), and motives for providing care (emotional bonds, lack of an alternative, too high costs of professional care, by request of cared-for person, by chance, or economic benefits), as well as the number of persons living with the cared-for person, care duration (in months), and care intensity (number of hours and number of nights per week). In addition, needs of the cared-for person (health, personal, mobility, emotional, housework, management of finances, financial support) and perceived importance of supportive services (information, training in caring, equipment to facilitate the caring process, financial support, rehabilitation at home, support in logistics of caring, respite care, transportation, opportunity to have more time, placement of the older person at nursing home) were included, with each element coded as a binary indicator, where zero indicated low or no need or importance, and one indicated high need or importance. Finally, we included the FCs' self-evaluated health status and his or her self-rated quality of life, each rated on a 5-point scale: very good (assigned value $=1$ ), good (assigned value $=2$ ), neither good nor bad (assigned value $=3$ ), bad (assigned value $=4$ ), or very bad (assigned value $=5$ ).

Additionally, FCs' answers to questions assessing the "positive value of care" according to the COPE questionnaire were taken into account: 1) Do you feel you cope well as a caregiver? 2) Do you find caregiving worthwhile? 3) Do you have a good relationship with the person you care for? 4) Do you feel that anyone appreciates you as a caregiver? as well as the "quality of support": 1) Do you feel well supported by your family? 2) Do you feel well supported by your friends and/or neighbors? 3) Do you feel well supported by health and social services? 4) Overall, do you feel well supported in your role of caregiver? Each of these questions could be answered as "never" or "not applicable" (assigned 
Table I Characteristics of family carers of geriatric inpatients $(\mathrm{N}=100)$

\begin{tabular}{|c|c|c|c|c|c|}
\hline Characteristics & $\begin{array}{l}\text { No of } \\
\text { missing cases }\end{array}$ & $\begin{array}{l}\text { All, } \\
\mathrm{N}=100\end{array}$ & $\begin{array}{l}\text { Lower NloC, } \\
\mathrm{n}=54\end{array}$ & $\begin{array}{l}\text { Higher NloC, } \\
n=46\end{array}$ & $P$-value \\
\hline Age (years), mean \pm standard deviation (SD) & 0 & $57.2 \pm 10.6$ & $56.4 \pm 11.2$ & $58.1 \pm 9.8$ & 0.304 \\
\hline Female $(\%)$ & 0 & 66.0 & 59.3 & 73.9 & 0.123 \\
\hline Married (\%) & 0 & 65.0 & 63.0 & 67.4 & 0.4 \\
\hline Urban place of residence (\%) & 0 & 85.0 & 88.9 & 82.6 & 0.42 \\
\hline \multicolumn{6}{|l|}{ Employment (\%) } \\
\hline Not employed & 0 & 53.0 & 42.6 & 65.2 & \\
\hline Part-time employed & & 12.0 & 16.7 & 6.5 & 0.059 \\
\hline Full-time employed & & 35.0 & 40.7 & 3.3 & \\
\hline Co-residence of carer with older person (\%) & 0 & 60.0 & 61.1 & 58.7 & 0.758 \\
\hline Number of persons living with older person, mean \pm SD & 0 & $1.3 \pm 1.1$ & $1.2 \pm 1.2$ & $1.3 \pm 1.1$ & 0.66 \\
\hline \multicolumn{6}{|l|}{ Cared-for person lives (\%) } \\
\hline With spouse & 0 & 26.0 & 25.9 & 26.1 & 0.985 \\
\hline With child & 0 & 46.0 & 44.4 & 47.8 & 0.735 \\
\hline With grandchild & 0 & 20.0 & 20.4 & 19.6 & 0.92 \\
\hline With other relative & 0 & 10.0 & 7.4 & 13.0 & 0.349 \\
\hline With paid carer & 0 & 3.0 & 1.9 & 4.4 & 0.466 \\
\hline \multicolumn{6}{|l|}{ Carer's education (\%) } \\
\hline Primary & 0 & 9.0 & 7.4 & 10.9 & \\
\hline Secondary & & 61.0 & 59.3 & 63.0 & 0.662 \\
\hline Higher & & 30.0 & 33.3 & 26.1 & \\
\hline \multicolumn{6}{|l|}{ Motives for caring (\%) } \\
\hline Emotional bonds & 0 & 69.0 & 83.3 & 52.2 & $<0.001$ \\
\hline There was no alternative & 0 & 62.0 & 61.1 & 63.0 & 0.842 \\
\hline Too high costs of professional care & 0 & 41.0 & 42.6 & 39.1 & 0.725 \\
\hline Request of older person & 0 & 38.0 & 42.6 & 32.6 & 0.305 \\
\hline By chance & 0 & 11.0 & 13.0 & 8.7 & 0.496 \\
\hline Economic benefits & 0 & 5.0 & 7.4 & 2.2 & 0.231 \\
\hline Duration of caring in years, mean $\pm S D$ & 0 & $3.3 \pm 2.8$ & $3.4 \pm 2.7$ & $3.3 \pm 3.0$ & 0.671 \\
\hline Number of care hours a week, mean \pm SD & 0 & $81.6 \pm 65.1$ & $69.3 \pm 63.9$ & $96.1 \pm 64.1$ & 0.007 \\
\hline Number of nights a week for caring, mean \pm SD & 0 & $3.3 \pm 3.4$ & $2.7 \pm 3.3$ & $4.0 \pm 3.4$ & 0.06 \\
\hline \multicolumn{6}{|l|}{ Needs of older person for help (\%) } \\
\hline Health needs & 0 & 95.0 & 90.7 & 100.0 & 0.034 \\
\hline Personal/physical help & 0 & 86.0 & 79.6 & 93.5 & 0.046 \\
\hline Mobility & 0 & 87.0 & 81.5 & 93.5 & 0.075 \\
\hline Emotional needs & 0 & 88.0 & 83.3 & 93.5 & 0.119 \\
\hline Domestic/housework & 0 & 87.0 & 85.2 & 89.1 & 0.558 \\
\hline Management of finances & 0 & 79.0 & 74.1 & 84.8 & 0.19 \\
\hline Financial support & 0 & 59.0 & 48.2 & 71.7 & 0.01 \\
\hline \multicolumn{6}{|l|}{ Importance of possible services (\%) } \\
\hline Information about available services & 0 & 62.0 & 64.8 & 58.7 & 0.529 \\
\hline Information about the disease of elder & 0 & 63.0 & 68.5 & 56.5 & 0.215 \\
\hline Training to develop my skills in caring & 0 & 50.0 & 57.4 & 41.3 & 0.108 \\
\hline Equipment to facilitate caring & 0 & 40.0 & 42.6 & 37.0 & 0.566 \\
\hline Financial support of caring process & 0 & 24.0 & 18.5 & 30.4 & 0.164 \\
\hline Rehabilitation of elder at home & 0 & 45.0 & 46.3 & 43.5 & 0.777 \\
\hline Support in logistics of caring & 0 & 40.0 & 35.2 & 45.7 & 0.286 \\
\hline $\begin{array}{l}\text { Temporary placement of elder in nursing home to } \\
\text { have break from caring }\end{array}$ & 0 & 23.0 & 20.4 & 26.1 & 0.498 \\
\hline Opportunity to take break from caring & 0 & 65.0 & 53.7 & 78.3 & 0.01 \\
\hline Transportation & 0 & 32.0 & 31.5 & 32.6 & 0.904 \\
\hline Opportunity to have more time for myself & 0 & 53.0 & 48.2 & 58.7 & 0.292 \\
\hline Placement of elder at nursing home & 0 & 10.0 & $1 \mathrm{I} . \mathrm{I}$ & 8.7 & 0.688 \\
\hline \multicolumn{6}{|l|}{ Carer's self-evaluated health (\%) } \\
\hline Very good or good & 0 & 36.0 & 48.2 & 21.7 & \\
\hline Fair & 0 & 47.0 & 40.7 & 54.4 & \\
\hline Bad or very bad & 0 & 17.0 & $1 \mathrm{I} .1$ & 23.9 & 0.035 \\
\hline
\end{tabular}


Table I (Continued)

\begin{tabular}{|c|c|c|c|c|c|}
\hline Characteristics & $\begin{array}{l}\text { No of } \\
\text { missing cases }\end{array}$ & $\begin{array}{l}\text { All, } \\
\mathrm{N}=100\end{array}$ & $\begin{array}{l}\text { Lower NloC, } \\
n=54\end{array}$ & $\begin{array}{l}\text { Higher NloC, } \\
n=46\end{array}$ & $P$-value \\
\hline \multicolumn{6}{|c|}{ Carer's self-evaluated quality of life (\%) } \\
\hline Very good or good & 0 & 52.0 & 61.1 & 41.2 & \\
\hline Fair & 0 & 43.0 & 37 & 50.0 & 0.171 \\
\hline Bad or very bad & 0 & 5.0 & 1.9 & 8.8 & \\
\hline \multicolumn{6}{|c|}{ Answers to the questions of the COPE "positive value of care" subscale } \\
\hline \multicolumn{6}{|c|}{ Do you feel you cope well as a caregiver? (\%) } \\
\hline Never or sometimes & 0 & 23.0 & 9.3 & 39.1 & $<0.001$ \\
\hline Often or always & 0 & 77.0 & 90.7 & 60.9 & \\
\hline \multicolumn{6}{|c|}{ Do you find caregiving worthwhile? (\%) } \\
\hline Never or sometimes & 0 & 23.0 & 18.5 & 28.3 & 0.248 \\
\hline Often or always & 0 & 77.0 & 81.5 & 71.7 & \\
\hline \multicolumn{6}{|c|}{ Do you have a good relationship with the person you care for? (\%) } \\
\hline Never or sometimes & 0 & 18.0 & 14.8 & 21.7 & 0.369 \\
\hline Often or always & 0 & 82.0 & 85.2 & 78.3 & \\
\hline \multicolumn{6}{|c|}{ Do you feel that anyone appreciates you as a caregiver? (\%) } \\
\hline Never or sometimes & 0 & 47 & 51.9 & 41.3 & 0.292 \\
\hline Often or always & 0 & 53 & 48.1 & 58.7 & \\
\hline \multicolumn{6}{|c|}{ Answers to the questions of the COPE "quality of support" subscale } \\
\hline \multicolumn{6}{|c|}{ Do you feel well supported by your family? (\%) } \\
\hline Never or sometimes & 0 & 45.0 & 35.2 & 56.5 & 0.032 \\
\hline Often or always & 0 & 55.0 & 64.8 & 43.5 & \\
\hline \multicolumn{6}{|c|}{ Do you feel well supported by your friends and/or neighbors? (\%) } \\
\hline Never or sometimes & 0 & 70.0 & 63.0 & 78.3 & 0.096 \\
\hline Often or always & 0 & 30.0 & 37.0 & 21.7 & \\
\hline \multicolumn{6}{|c|}{ Do you feel well supported by health and social services? } \\
\hline Never or sometimes & 0 & 52.0 & 53.7 & 50.0 & $0.7 \mathrm{II}$ \\
\hline Often or always & 0 & 48.0 & 46.3 & 50.0 & \\
\hline \multicolumn{6}{|c|}{ Overall, do you feel well supported in your role of caregiver? (\%) } \\
\hline Never or sometimes & 0 & 54.0 & 37.0 & 73.9 & $<\mathbf{0 . 0 0 1}$ \\
\hline Often or always & 0 & 46.0 & 63.0 & 26.1 & \\
\hline
\end{tabular}

Notes: Results of the univariate analyses examining relationships between higher negative impact of care (NloC) and each characteristic. Bold values indicate significant relationships at $P<0.05$.

value $=1$ ); "sometimes" (assigned value $=2$ ); "often" (assigned value $=3$ ); or "always" (assigned value $=4$ ).

\section{Geriatric inpatients' data}

In addition to carers' data, inpatient-related characteristics were also included as potential predictors (Table 2). These included inpatient's age (in years), gender (male or female), number of years spent in education, place of residence (urban or rural), mode of living (alone or with family), a highstress situation in the recent past (yes or no), and feelings of loneliness (never, sometimes, or often). Anthropometric measures collected were the body mass index (BMI) and the waist-to-hip ratio (WHR). Physical functional status was assessed using the Barthel inde $\mathrm{x}^{34}$ - an ordinal rating scale for basic activities of daily living (B-ADL): feeding, bathing, grooming, dressing, bowel control, bladder control, toilet use, transfer (bed to chair), mobility, and stair use - where the total score ranges from a minimum of 0 (complete dependence) to a maximum of 100 (complete independence). The ability to perform instrumental activities of daily living (I-ADL) was measured using the Duke OARS Assessment, ${ }^{35}$ where the total score ranges from 0 (lowest function) to 12 (highest function). Six domains of functions were covered, including preparing their own meals, shopping, handling their own money, using the telephone, and taking their own medicines. The risk of bed sores was evaluated using the Norton scale, where the total score ranges from 5 (highest risk) to 20 (no risk of bed sores). ${ }^{36}$ The severity of depression symptoms was evaluated using the 15-item Geriatric Depression Scale, where higher scores indicate more severe depression. ${ }^{37}$ Cognitive functions were assessed using the Clock Drawing Test, where the summary score ranges from 0 to 7 and higher scores indicate higher cognitive function, and the Mini Mental State Examination (MMSE), ${ }^{38}$ where the summary score ranges from 0 (the worst result) to 30 (the best result). Mobility, including the risk of falling, was assessed with the Timed Up and Go (TUG) test, ${ }^{39}$ which measures the seconds following the instruction to rise from 
Table 2 Characteristics of geriatric patients $(\mathrm{N}=100)$

\begin{tabular}{|c|c|c|c|c|c|}
\hline Characteristics & $\begin{array}{l}\text { No of } \\
\text { missing cases }\end{array}$ & $\begin{array}{l}\text { All, } \\
\mathrm{N}=100\end{array}$ & $\begin{array}{l}\text { Lower } \\
\text { NloC, } n=54\end{array}$ & $\begin{array}{l}\text { Higher } \\
\text { NloC, } n=46\end{array}$ & $P$-value \\
\hline Age (years), mean \pm standard deviation (SD) & No & $81.7 \pm 6.4$ & $81.4 \pm 6.2$ & $82.0 \pm 6.7$ & 0.508 \\
\hline Female $(\%)$ & No & 75.0 & 70.4 & 80.4 & 0.247 \\
\hline Number of years of education, mean \pm SD & No & $8.0 \pm 4.3$ & $8.1 \pm 4.5$ & $7.9 \pm 4.0$ & 0.96 \\
\hline Urban place of residence $(\%)$ & No & 59.0 & 70.4 & 45.7 & 0.012 \\
\hline Coresidence with family member (\%) & No & 78.0 & 74.1 & 82.6 & 0.304 \\
\hline High-stress situation in recent past (\%) & No & 25.0 & 27.8 & 21.7 & 0.487 \\
\hline Often feeling lonely (\%) & 4 & 15.4 & I5.4 & 15.9 & 0.318 \\
\hline Body mass index $\left(\mathrm{kg} / \mathrm{m}^{2}\right)$, mean $\pm \mathrm{SD}$ & 7 & $28.1 \pm 5.7$ & $27.5 \pm 5.7$ & $28.9 \pm 5.8$ & 0.36 \\
\hline Waist-to-hip ratio, mean \pm SD & I & $0.92 \pm 0.1$ & $0.92 \pm 0.1$ & $0.92 \pm 0.1$ & 0.599 \\
\hline Barthel index, mean $\pm S D$ & No & $69.3 \pm 31.8$ & $73.0 \pm 31.5$ & $64.9 \pm 32.0$ & 0.068 \\
\hline Instrumental activities of daily living (I-ADL), mean \pm SD & No & $4.7 \pm 3.9$ & $5.1 \pm 3.9$ & $4.3 \pm 3.8$ & 0.331 \\
\hline Norton scale, mean $\pm S D$ & No & $15.6 \pm 3.2$ & $16.1 \pm 3.0$ & $15.0 \pm 3.4$ & 0.069 \\
\hline Geriatric Depression Scale, mean \pm SD & II & $6.8 \pm 3.4$ & $6.3 \pm 3.1$ & $7.3 \pm 3.6$ & 0.213 \\
\hline Mini Mental State Examination, mean \pm SD & No & $17.0 \pm 7.6$ & $|7.9 \pm 8|$. & $15.9 \pm 7.0$ & 0.091 \\
\hline Clock Drawing Test, mean \pm SD & 3 & $2.4 \pm 2.6$ & $2.6 \pm 2.8$ & $2.2 \pm 2.3$ & 0.764 \\
\hline Timed Up and Go test (seconds), mean \pm SD & 18 & $27.4 \pm 13.6$ & $23.3 \pm 11.8$ & $32.2 \pm 14.2$ & $<0.001$ \\
\hline Speed of performing the Timed Up and Go test $(\mathrm{m} / \mathrm{s})$, mean \pm SD & No & $0.23 \pm 0.18$ & $0.28 \pm 0.2$ & $0.17 \pm 0.14$ & 0.003 \\
\hline Falls in the past year (\%) & No & 53.0 & 50.0 & 56.5 & 0.515 \\
\hline Postural hypotension (\%) & 10 & 27.8 & 34.7 & 19.5 & 0.109 \\
\hline Charlson index, mean \pm SD & No & $8.0 \pm 2.9$ & $8.0 \pm 2.7$ & $8.1 \pm 3.1$ & 0.886 \\
\hline Urine incontinence (\%) & No & 71.0 & 68.5 & 73.9 & 0.553 \\
\hline Bed sores (\%) & 1 & 7.1 & 5.7 & 8.7 & 0.556 \\
\hline Heart failure (\%) & No & 24.0 & 22.2 & 26.1 & 0.651 \\
\hline Dementia (\%) & No & 71.0 & 66.7 & 76.1 & 0.301 \\
\hline Cerebrovascular disease (\%) & No & 79.0 & 70.4 & 89.1 & 0.021 \\
\hline Chronic obstructive pulmonary disease (\%) & No & 3.0 & 3.7 & 2.2 & 0.654 \\
\hline Diabetes mellitus (\%) & No & 37.0 & 44.5 & 28.3 & 0.247 \\
\hline
\end{tabular}

Notes: Results of the univariate analyses examining relationships between higher negative impact of care (NloC) and each characteristic. Bold values indicate significant relationships at $P<0.05$.

a chair and walk at a comfortable and safe speed to a line that is $3 \mathrm{~m}$ away, turn around at the line, walk back, and sit down (the use of an assistance device was allowed if needed). The results were recalculated into speed of the whole TUG performance (in meters per second), which provided higher explanatory power than the untransformed variable. For 13 bedridden cases, we assigned a TUG speed of $0 \mathrm{~m} / \mathrm{s}$.

Multimorbidity was measured with the Charlson comorbidity index $(\mathrm{CCI}),{ }^{40}$ where the score ranges from a minimum of 0 to maximum of 31 , depending on the presence or absence of selected diseases (ie, heart failure, dementia, cerebrovascular disease, diabetes, chronic obstructive pulmonary disease, chronic kidney disease, and cancer, among others). Additionally, the presence of postural hypotension, falls in the previous year, urine incontinence, and bed sores was noted. All the data were routinely collected in all geriatric inpatients by the geriatric team (geriatricians, nurses, physiotherapists, and a psychologist).

\section{Statistical analysis}

First, univariate analyses were performed to test the significance of relationships between the binary indicator of the higher stress, ie, higher NIoC, and each of the carer-related variables (Table 1) or inpatient-related variables (Table 2). Second, computation-intensive, computer-assisted variable selection methods were used to 1) identify the optimal subset of predictors in a multiple logistic regression (LR) model of the higher stress from providing care and 2) validate the robustness of the final model. To this end, a large number of candidate LR models were estimated, where each of these models included a different subset of potential predictors. To reduce the computational burden, only those independent variables that achieved $P$-values $<0.2$ in the univariate analyses were included in this second-stage multivariate modeling. The best combination, ie, the subset of independent variables that provided the highest predictive power for the dependent variable in the final LR model, was determined according to the second-order variant of the Akaike Information Criterion (AICc), tailored for moderate sample sizes (if the number of observations divided by the number of parameters is $<40),{ }^{41}$ and the Bayesian Information Criterion (BIC) ${ }^{42}$ Both AICc and BIC aim at preventing overfitting by balancing the goodness-of-fit of the statistical model against its complexity. ${ }^{43}$ The same combination of five independent 
variables was identified as the best according to both of these information criteria. LR models with other possible subsets of predictors were considerably less supported by the data. ${ }^{41}$

The robustness and the out-of-sample predictive accuracy of the final LR model was tested with 10 -fold crossvalidation. ${ }^{44}$ To this end, the data were randomly divided into $\mathrm{K}=10$ equal subsets (each subset containing 10 observations), where $\mathrm{K}-1$ such subsets (90 observations) formed a training block (sample), and the remaining subset (10 observations) formed a testing sample. The LR model with the best predictors was estimated on a training block and its out-of-sample discriminative power was evaluated on the remaining subset of observations. The process was repeated $\mathrm{K}$ times on different training and testing samples. Bootstrapped confidence intervals (CIs) for the out-of-sample AUC measure, ie, average area under the receiver operating curve (ROC), were computed. ${ }^{45}$ Statistical analyses were performed with the STATA software version 14.0 (StataCorp LP, College Station, TX, USA).

\section{Results}

According to the AICc and BIC information criteria, the best LR model for predicting higher stress associated with providing care comprised of five predictors: 1) FCs' self-evaluated health status ( $\mathrm{OR}=2.28$; 95\% CI: 1.15-4.52), 2) FCs' selfappraisal of coping well as a caregiver (OR $=0.22 ; 95 \%$ CI: 0.1-0.52), 3) FCs' sense of overall support in their role as a caregiver $(\mathrm{OR}=0.35 ; 95 \% \mathrm{CI}: 0.18-0.70), 4)$ the number of care hours per week $(\mathrm{OR}=1.01 ; 95 \% \mathrm{CI}: 1.00-1.02)$, and 5 ) the speed of the patient's TUG performance (OR $=0.01$; 95\% CI: 0.00-0.48). Parameter estimates are presented in Table 3.

The marginal effects for each of the explanatory variables in the best LR model are depicted in Figure 1. Each panel represents the predicted probability of higher stress associated with providing care for all possible values of a best predictor, given that all other covariates are set to their average levels.

Table 3 Parameter estimation results for the best multiple logistic regression model of higher negative impact of care (NloC) among family carers (FCs) of geriatric patients

\begin{tabular}{lll}
\hline Variables & Parameter estimate & $P$-value \\
\hline Constant & 4.665 & 0.000 \\
FC's self-evaluated health & 0.822 & 0.019 \\
FC's self-appraisal of coping & -1.492 & $<0.001$ \\
well as a caregiver & & \\
FC's sense of overall support & -1.042 & 0.003 \\
in his or her role as a caregiver & & \\
Number of care hours a week & 0.010 & 0.011 \\
Timed Up and Go test & -4.279 & 0.018 \\
\hline
\end{tabular}

The predicted probability that an FC experiences a high NIoC varies in parallel to his or her self-evaluated health status (panel A). The probability rises from the level of approximately 0.15 for carers that rate their health as "very good" to approximately 0.8 for those who perceive their health as "very bad." FCs' distress is strongly dependent on the selfperception of "coping well as a caregiver" (panel B). Thus, FCs almost always (predicted probability equal to 0.95 ) feel stressed in their roles as caregivers if they sense that they don't cope well with their tasks. However, the probability of distress drops to $<0.2$ if they perceive they handle the caregiver's role well. Subjective perception of overall support, whether from family, neighbors, friends, or formal services, considerably alleviates the risk of high NIoC, as the probability drops from approximately 0.8 to 0.15 with greater perception of support (panel C). On the other hand, an objective factor that affects the caregiver's subjective burden is the number of care hours per week. However, the increase in probability of experiencing distress is not extremely high; it changes from approximately 0.25 for carers that provide care for approximately 10 hours/wk to 0.6 for those FCs who live with their seniors and care for them around the clock on a daily basis (panel D). Interestingly, after controlling for the factors previously mentioned, the cared-for person's motor function turned out to be the only inpatient-related predictor that exerts an impact on FC (panel E). Those FCs who provide care for bedridden persons are more likely to be distressed, with a probability of 0.65 . On the other hand, the FCs who provide care for persons who are able to perform the TUG test very quickly were significantly less likely to be distressed.

The discriminative power of the final LR model was very high. In-sample AUC statistics amounted to 0.86, and the average out-of-sample AUC obtained with the 10-fold cross-validation was equal to 0.83 (95\% CI: $0.77-0.87$ ). Accordingly, the model is very robust and can be used for predictive purposes.

Figure 2 provides insights into classification of FCs according to the optimal LR model. The risk of high distress among FCs results from a particular combination of observable values for five best predictors. The individual graphs depict combinations of TUG test outcomes (on the vertical axis) and number of care hours per week (on the horizontal axis) for which an FC experiences high NIoC (orange area), based on specific answers to questions: "Overall, do you feel well supported in your role of caregiver?" "Do you feel you cope well as a caregiver?" "How do you evaluate your overall health?" For example, for those FCs who state that they "sometimes" cope well as caregiver, "often" feel overall well-supported and evaluate their health 


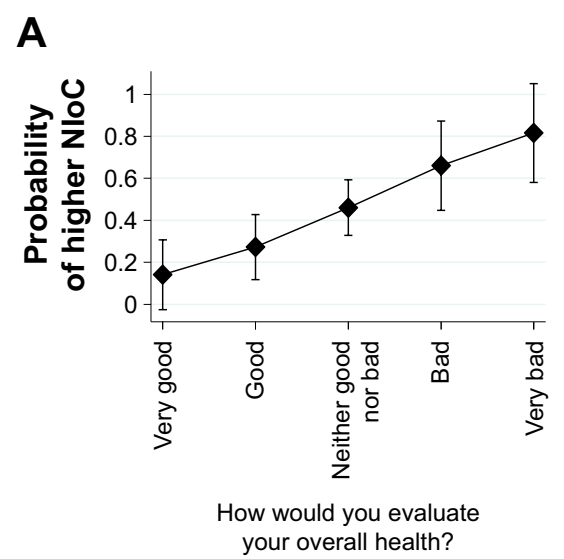

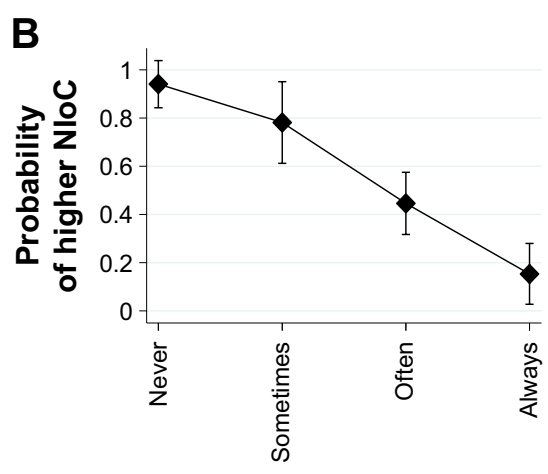

Do you feel you cope well as a caregiver?

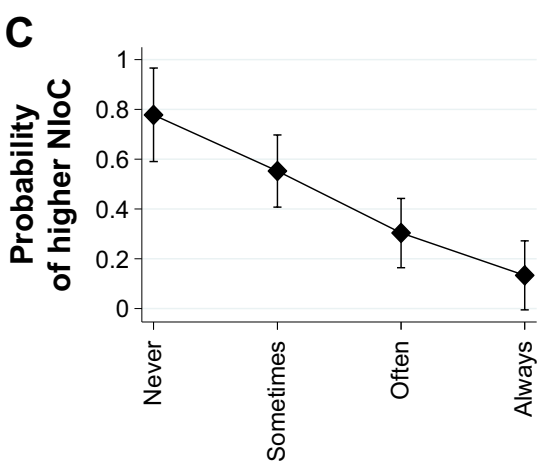

Do you feel well supported in your role of caregiver?
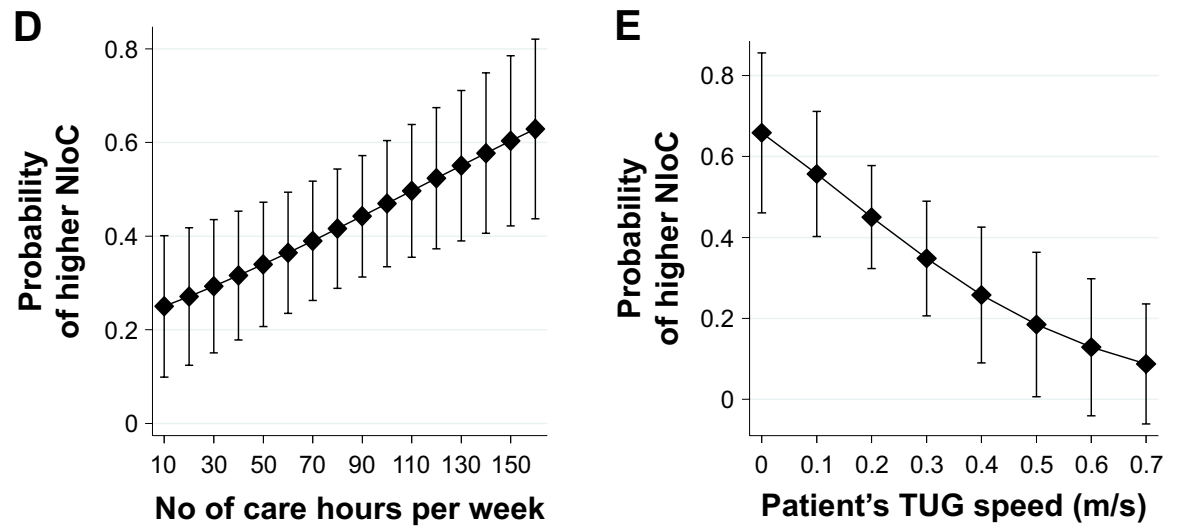

Figure I (A-E) Predicted probabilities for higher negative impact of care (NloC) among family carers of geriatric patients: results from the best multiple logistic regression model. Note: Vertical bars denote $95 \%$ confidence interval $(\mathrm{Cl})$.

as "very good", the upper right orange area of the graph corresponds to the pairs of TUG outcomes and numbers of care hours that classifies an FC as being highly stressed (panel A). This orange area shrinks if an FC "often" copes well as a caregiver and "sometimes" feels well-supported (panel B) and broadens considerably if an FC "often" copes well as a caregiver, but "never" feels well-supported (panel C). Those carers "sometimes" cope well as a caregiver, "sometimes" feel well-supported, and evaluate their health as "bad" are nearly always classified as distressed by the care needs of their seniors, irrespective of TUG outcome or number of care hours (panel H).

\section{Discussion}

Systematic assessment of distress suffered by FCs of the disabled, comorbid, and oldest-old persons is often ignored in routine clinical practice, usually due to time deficiency or absence of simple and feasible evaluation tools. On the other hand, it is known that the chronic stress of caregiving that results from persistent physical and mental strain can lead to several diseases and dysfunctions, such as depression ${ }^{46}$ or impaired endocrine and immune function. ${ }^{47}$ Thus, FCs can be called "invisible second patients," who - at the same time - have to play the key role in ensuring the quality of life of ill older people in their home environment. ${ }^{48}$

Although in our empirical study, we took into account a very long list of potential explanatory factors, the application of statistical information criteria in the multivariate analysis allowed us to identify a short list of the five most important variables that enable us to successfully predict distress among FCs. Moreover, reliance on the information criteria in the variable selection process also allowed us to overcome limitations of the widely used forward or backward elimination methods, in particular the arbitrarily chosen confidence levels that must be appropriately corrected for the whole decision process and the poor performance of the stepwise methods in the presence of multicollinearity. ${ }^{49}$

Our study shows that the less supported FCs feel and the less convinced they are that they cope well as caregivers, the more they will probably be stressed by their circumstances. Formal supports such as institutionalization, financial assistance, or counselling are known to reduce the burden on $\mathrm{FCs},{ }^{50}$ and the informal physical, emotional, and informational support reflected in the presence of a strong social 


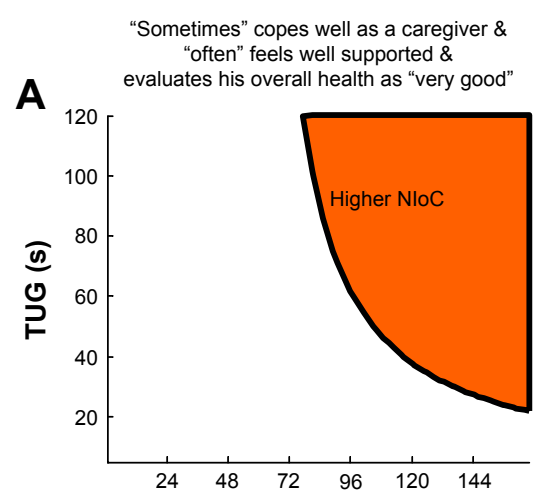

Number of care hours per week

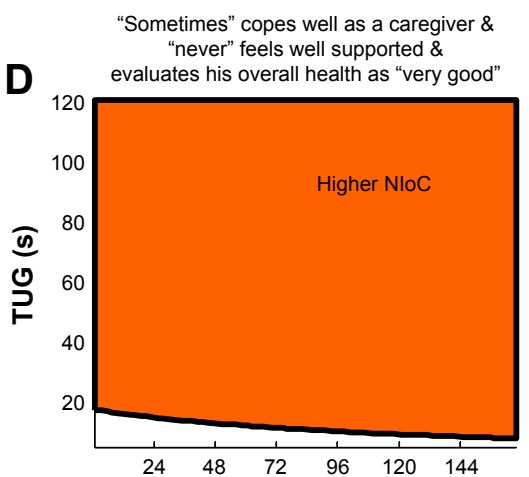

Number of care hours per week

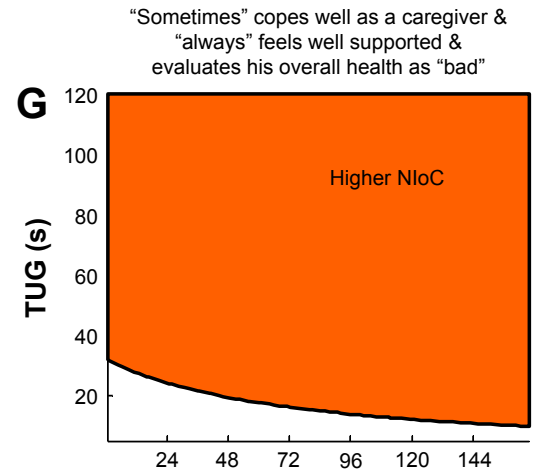

Number of care hours per week

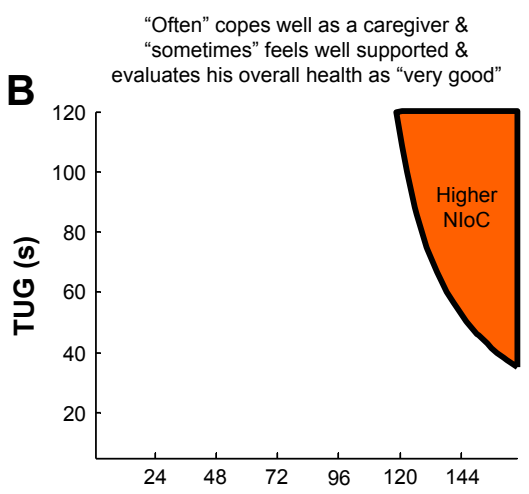

Number of care hours per week

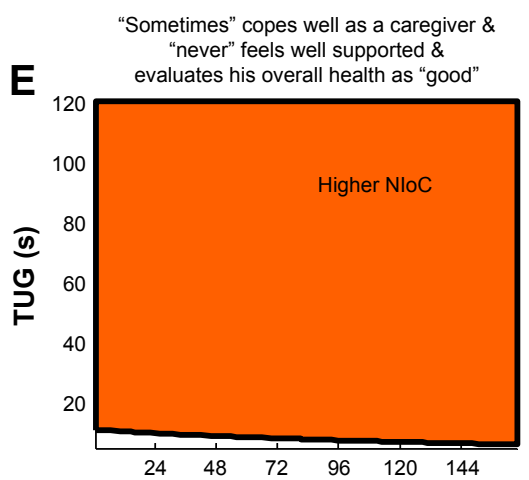

Number of care hours per week

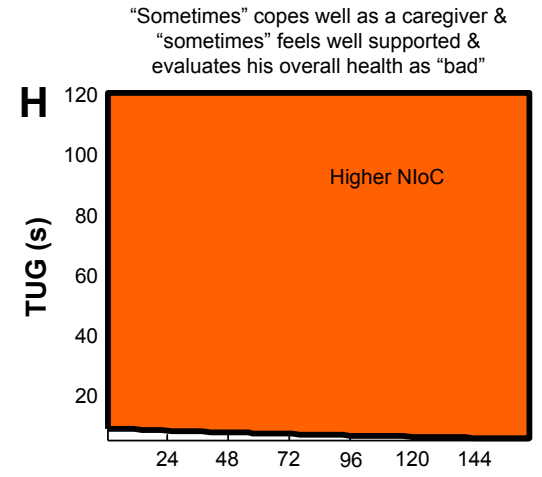

Number of care hours per week

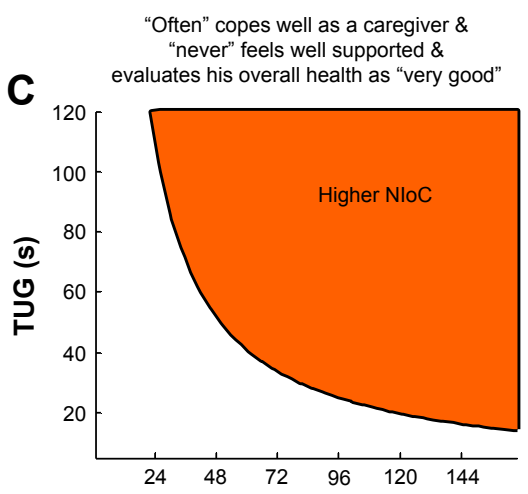

Number of care hours per week

"Sometimes" copes well as a caregiver \& "often" feels well supported \&

F evaluates his overall health as "neither good nor bad"

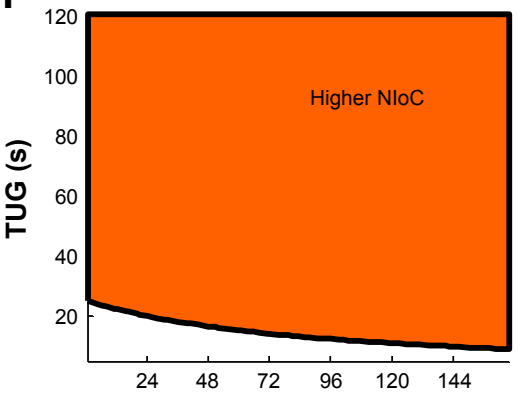

Number of care hours per week

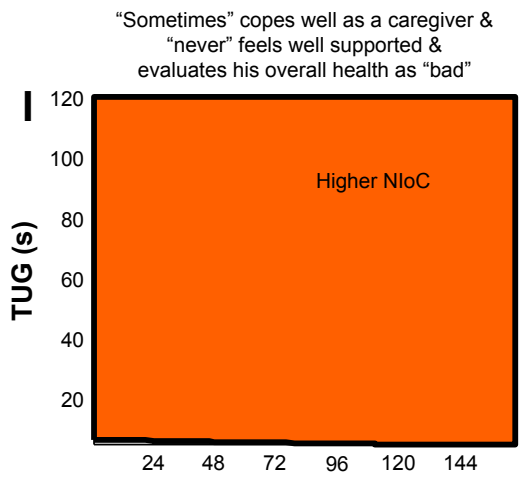

Number of care hours per week

Figure 2 (A-I) Combination of risk factors discriminating family carers (FCs) with higher negative impact of care (NloC) from FCs with lower NloC: results from the best multiple logistic regression model.

network eases FCs' distress. ${ }^{51,52}$ In the multivariate analysis, a predictor defined as a degree of "overall support" encompassed all of the aforementioned elements. This complex notion turned out to possess better predictive power for higher distress in FCs than other much more precise verbalizations of support channels (ie, support from family, friends or neighbors, health, and social services). Our results also indicate that the FC's level of stress is relieved by the ability to control and manage the challenges of a caregiver's role and, thus, to cope well with the needs of care recipients. This finding is in line with the observation that stressors in one domain of an FC's life usually compound or exacerbate difficulties in coping with the demands in other domains of life. ${ }^{53}$ Thus, the distress suffered by FCs is directly related to their intrinsic perceived ability to handle the demands associated with providing care. As FCs usually face multifaceted physical, emotional, social, or spiritual challenges, targeted and timely interventions aimed at educating FCs on how to cope more efficiently with the everyday demands of a caregiver's role are of great importance. ${ }^{54}$

Another explanatory variable that is independently associated with higher distress in FCs is his or her self-evaluated 
health. This relationship may not represent one-directional causality, as the physical and emotional strain in caregiving is known to result in deterioration of the carer's health. ${ }^{55,56}$ We show that subjective perception of the FCs own health status is independently associated with the probability of distress from providing care. If an FC "sometimes" feels well supported, "sometimes" copes well as a caregiver and perceives his or her health as "bad" or "very bad," he or she will have a higher NIoC, irrespective of the values taken by other covariates in the final model. Our results also show that the probability of higher distress in FCs increases with the number of care hours per week. This objective measure of FCs' involvement is already known to be associated with subjective appraisal of carer's burden, because fatigue and burnout escalates if the caring is relentlessly time consuming. ${ }^{52,57}$

In the literature, there is conflicting evidence about relationships between distress suffered by FCs and objective characteristics of the care recipients. ${ }^{6}$ The study of Garlo et $\mathrm{al}^{58}$ showed that there are no independent associations between sociodemographic or health-related characteristics of older cared-for persons with advanced chronic diseases and the burden from providing care, a result which might be explained by a carer's ability to adapt to his or her circumstances. Our results from the multivariate analysis also do not provide evidence of any significant relationships between a higher NIoC among FCs and a declared disability or a diagnosed disease/disorder, including dementia, in cared-for persons. Slow motor performance, measured with the speed of the TUG test, was the only patient-related factor in the multivariate model that best predicted higher distress among FCs. Gait speed or motor retardation is usually known to be valid as indicators of overall disability and even risk of death in older adults ${ }^{59,60}$ as well as they help to predict the subjective well-being. ${ }^{61}$ Our results are consistent with this, as only the TUG speed, representing the motor function of the care recipient, was selected for the final model, irrespective of dementia diagnosis, comorbidity level measured with the Charlson index, or the presence of other disabilities assessed with the Barthel or I-ADL indexes. Similar findings were reported in a study based on older patients with cancer, although the motor retardation was measured with a different instrument. ${ }^{22}$ Poor motor function of cared-for persons was already shown to exert an independent effect on a carer's burden in studies based on patients with Parkinson's disease ${ }^{29}$ or with multiple sclerosis. ${ }^{62}$ According to Pike et al, ${ }^{63}$ patients with greater walking impairment more often require additional caregiver support, visit healthcare professionals more frequently, and require more nondisease modifying drugs.
Our findings indicate that the summed-up effect of a wide spectrum of dysfunctions might be expressed with a single variable measuring motor speed. To our knowledge, this significant independent effect of poor motor function in the oldest, most comorbid, and frail adults on the probability of high distress in their FCs is novel in the literature.

Our study has some limitations that should be addressed. First, in our study we did not measure the caregiver's functional status (including motor function), depression, or cognition, and these characteristics might potentially influence the high score on the NIoC. ${ }^{27}$ Second, the crosssectional setup of our analysis does not permit statistical inference about causal, unidirectional relationships between some explanatory variables and higher distress in an FC. As mentioned previously, self-evaluation of health may be treated as both a cause and an effect of distress among FCs. Analogously, the inability to cope well with the caregiver's demands may increase a subjective appraisal of burden, whereas the converse may also be true, and a distressed FC may underrate his or her ability to stand up to the challenges of the caregiver's role. Regardless of this fact, both these explanatory variables proved to very successfully indicate the risk of distress among FCs. Third, we relied on a relatively low sample size. However, the obtained LR model allowed for a very good discrimination between lower and higher stress associated with caregiving and the high robustness of the observed relationships was successfully confirmed for out-of-sample observations using the statistical method of cross-validation.

\section{Conclusion}

This study provides new insights into the process of simple and feasible identification of those FCs who feel highly stressed by providing care and, hence, warrant timely and careful consideration of their situation and circumstances. According to the optimal model, a caregiver's high NIoC can be independently predicted by lower self-evaluation of health; poor subjective self-appraisal of coping well as a caregiver; lower intrinsic sense of general support; and two objective factors: higher number of care hours per week and lower motor function of the cared-for person. Among the predictive variables in the model, motor retardation as assessed by the TUG test was the only patient-related predictor of higher NIoC. This is a novel result since the majority of studies focuses mainly on the presence of dementia or different dementia-related factors for the burden suffered by FCs of older adults, ${ }^{16,24,26}$ whereas the beneficial effects of conventional case management are shown to be limited. ${ }^{64}$ 
Thus, we show that educational initiatives aimed at promotion of suitably tailored physical exercises for older adults could be beneficial not only for the cared-for persons, but also for their carers. The practical clinical implication from our study is to enhance the mobility of hospitalized older patients by kinesitherapeutic treatment within a comprehensive geriatric approach. This is a challenging, but also rewarding task that has the potential to alleviate silent distress in FCs.

\section{Acknowledgments}

The study was supported by the Medical University of Bialystok, Poland (project no: N/ST/ZB/16/002/3301). No research funds were received by any author of this article.

\section{Disclosure}

The authors report no conflicts of interest in this work.

\section{References}

1. Oeppen J, Vaupel JW. Broken limits to life expectancy. Science. 2002; 296(5570):1029-1031.

2. European Commission. Health and long-term care in the European Union, Report, Special Eurobarometr 2007 283/Wave 67.3., Brussels.

3. Karlamangla A, Tinetti M, Guralnik J, Studenski S, Wetle T, Reuben D. Comorbidity in older adults: nosology of impairment, diseases, and conditions. J Gerontol A Biol Sci Med Sci. 2007;62(3):296-300.

4. Lamura G, Döhner H, Kofahl C. Family Carers of Older People in Europe. Berlin: LIT Verlag; 2008.

5. Bień B, editor. Family Caregiving for the Elderly in Poland. Białystok: Wydawnictwo Trans Humana; 2006.

6. Borgermans L, Nolan M, Philp I. Chapter 1: Europe. In: Philp I, editor. Family Care of Older People in Europe. Amsterdam Berlin Oxford Tokyo Washington, DC: IOS Press Ohmsa; 2001:1-26.

7. Lamura G, Mnich E, Nolan M, et al; EUROFAMCARE Group. Family carers' experiences using support services in Europe: empirical evidence from the EUROFAMCARE Study. Gerontologist. 2008;6:752-777.

8. Ganapathy V, Graham GD, DiBonaventura MD, Gillard PJ, Goren A, Zorowitz RD. Caregiver burden, productivity loss, and indirect costs associated with caring for patients with poststroke spasticity. Clin Interv Aging. 2015;6(10):1793-1802.

9. Principi A, Lamura G, Sirolla C, et al. Work restrictions experienced by midlife family caregivers of older people. Ageing Soc. 2014;34(2): 209-231.

10. Bauer JM, Sousa-Poza A. Impacts of informal caregiving on caregiver employment, health, and family. J Popul Ageing. 2015;8(3):113-145.

11. Adelman RD, Tmanova LL, Delgado D, Dion S, Lachs MS. Caregiver burden. A clinical review. JAMA. 2014;311(10):1052-1059.

12. Pinquart M, Sörensen S. Differences between caregivers and noncaregivers in psychological health and physical health: a meta-analysis. Psychol Aging. 2003;18(2):250-267.

13. Vellone E, Fida R, Cocchieri A, Sili A, Piras G, Alvaro R. Positive and negative impact of caregiving to older adults: a structural equation model. Prof Inferm. 2011;64(4):237-248.

14. Arai Y, Zarit SH, Sugiura M, Washio M. Patterns of outcome of caregiving for the impaired elderly: a longitudinal study in rural Japan. Aging Ment Health. 2002;6:39-46.

15. Zarit SH, Reever KE, Bach-Peterson J. Relatives of the impaired elderly: correlates of feelings of burden. Gerontologist. 1980;20(6):649-655.

16. Kim SW, Kim JM, Stewart R, et al. Correlates of caregiver burden for Korean elders according to cognitive and functional status. Int J Geriatr Psychiatry. 2006;21(9):853-861.
17. Tang JY, Ho AH, Luo H, et al. Validating a Cantonese short version of the Zarit Burden Interview (CZBI-Short) for dementia caregivers. Aging Ment Health. 2016;20(9):996-1001.

18. Yeh PM, Chang Y. Use of Zarit Burden Interview in analysis of family caregivers' perception among Taiwanese caring with hospitalized relatives. Int J Nurs Pract. 2015;21(5):622-634.

19. McKee KJ, Philp I, Lamura G, et al; on behalf of the COPE Partnership. The COPE index - a first stage assessment of negative impact, positive value and quality of support of caregiving in informal carers of older people. Aging Ment Health. 2003;7(1):39-52.

20. Balducci C, Mnich E, McKee K, et al. Negative impact and positive value in caregiving: validation of the COPE index in a six-country sample of carers. Gerontologist. 2008;48:276-286.

21. Krug K, Miksch A, Peters-Klimm F, Engeser P, Szecsenyi J. Correlation between patient quality of life in palliative care and burden of their family caregivers: a prospective observational cohort study. BMC Palliat Care. 2016;15:4

22. Rajasekaran T, Tan T, Ong WS, et al. Comprehensive Geriatric Assessment (CGA) based risk factors for increased caregiver burden among elderly Asian patients with cancer. J Geriatr Oncol. 2016;7(3):211-218.

23. Feast A, Orrell M, Charlesworth G, et al. Behavioural and psychological symptoms in dementia and the challenges for family carers: systematic review. Br J Psychiatr. 2016;208(5):429-434.

24. Qing L, Shuling L, Huo YR, et al. Comprehensive analysis of patients and caregiver predictors for caregiver burden, anxiety and depression in Alzheimer's disease. J Clin Nurs. 2015;24:2668-2678.

25. Rinaldi P, Spazzafumo L, Mastriforti R, et al. Predictors of high level of burden and distress in caregivers of demented patients: results of an Italian multicenter study. Int J Geriatr Psychiatry. 2005;20:168-174.

26. Shankar KN, Hirschman KB, Hanlon A, Naylor MD. Burden among caregivers of elders who were cognitively impaired at the time of hospitalization: a cross-sectional analysis. J Am Geriatr Soc. 2014;62(2): 276-284.

27. De Fazio P, Ciambrone P, Cerminara G, et al. Depressive symptoms in caregivers of patients with dementia: demographic variables and burden. Clin Interv Aging. 2015;10:1085-1090.

28. Shilling V, Mattews L, Jenkins V, Fallowfield L. Patient-reported outcome measures for cancer caregivers: a systematic review. Qual Life Res. 2016. doi:10.1007/s11136-016-1239-0.

29. Kudlicka A, Clare L, Hindle JV. Quality of life, health status and caregiver burden in Parkinson's disease: relationship to executive functioning. Int J Geriat Psychiatry. 2014;29:68-76.

30. Sakakibara K, Kabayama M, Ito I. Experiences of "endless" caregiving of impaired elderly at home by family caregivers: a qualitative study. BMC Res Notes. 2015;8:827.

31. Williams SW, Williams CS, Zimmerman S, Munn J, Dobbs D, Sloane PD. Emotional and physical health of informal caregivers of residents at the end of life: the role of social support. J Gerontol B Psychol Sci Soc Sci. 2008;63(3):S171-S183.

32. Hazzard WR. Introduction: the practice of geriatric medicine. In: Hazzard WR, Bierman EL, Blass JP, Ettinger WH Jr, Halter JB, editors. Principles of Geriatric Medicine and Gerontology. 3rd ed. New York, NY: McGraw-Hill, Inc; 1994.

33. Rubenstein LZ. An overview of comprehensive geriatric assessment. In: Rubenstein LZ, Wieland D, Bernabei R, editors. Geriatric Assessment Technology. The State of the Art. Milan: Editrice Kurtis; 1995:1-9.

34. Mahoney FI, Barthel DW. Functional evaluation: The Barthel Index. Md State Med J. 1965;14:61-65.

35. Fillenbaum GG, Smyer MA. The development, validity, and reliability of the Oars Multidimensional Functional Assessment Questionnaire. J Gerontol. 1981;36:428-434.

36. Norton D, McLaren R, Exton-Smith A. An Investigation of Geriatric Nursing Problems in Hospital. London: National Corporation for the Care of Old People; 1962.

37. Sheikh JI, Yesavage JA. Geriatric Depression Scale (GDS): recent evidence and development of a shorter version. Clin Gerontol. 1986;5: $165-173$. 
38. Folstein MF, Folstein SE, McHugh PR. "Mini-mental state". A practical method for grading the cognitive state of patients for the clinician. Psychiatr Res. 1975;12(3):189-198.

39. Podsiadlo D, Richardson S. The timed up \& go: a test of basic functional mobility for frail elderly persons. J Am Geriatr Soc. 1991;39(2):142-148.

40. Charlson ME, Pompei P, Ales KL, MacKenzie CR. A new method of classifying prognostic comorbidity in longitudinal studies: development and validation. J Chronic Dis. 1987;40:373-383.

41. Burnham KP, Anderson DR. Model Selection and Multimodel Inference. A Practical Information-Theoretic Approach. New York, NY: Springer; 2002.

42. Neath AA, Cavanaugh JE. The Bayesian information criterion: background, derivation, and applications. Wiley Interdiscip Rev Computat Stat. 2012;4(2):199-203.

43. Konishi S, Kitagawa G. Information Criteria and Statistical Modelling. New York, NY: Springer; 2008.

44. Hastie T, Tibshirani R, Friedman J. The Elements of Statistical Learning: Data Mining, Inference, and Prediction. 2nd ed. New York, NY: Springer; 2009.

45. Hanley JA, McNeil BJ. The meaning and use of the area under a receiver operating characteristic (ROC) curve. Radiology. 1982;143:29-36.

46. Thompson A, Fan MY, Unützer J, Katon W. One extra month of depression: the effects of caregiving on depression outcomes in the IMPACT trial. Int J Geriatr Psychiatry. 2008;23(5):511-516.

47. Lovell B, Wetherell MA. The cost of caregiving: endocrine and immune implications in elderly and non elderly caregivers. Neurosci Biobehav Rev. 2011;35(6):1342-1352.

48. Brodaty H, Donkin M. Family caregivers of people with dementia. Dialogues Clin Neurosci. 2009;11(2):217-228.

49. Gentle JE, Härdle WK, Mori Y. Handbook of Computational Statistics. Concepts and Methods. Berlin: Springer; 2012.

50. Gaugler JE, Roth DL, Haley WE, Mittleman MS. Can counselling and support reduce burden and depressive symptoms in caregivers of people with Alzheimer's disease during the transition to institutionalization? Results from the New York University caregiver intervention study. J Am Geriatr Soc. 2008;56:421-428.

51. Dunkin JJ, Anderson-Hanley C. Dementia caregiver burden: a review of the literature and guidelines for assessment and intervention. Neurology. 1998;51(suppl 1):S53-S60.
52. Yu H, Wang X, He R, Liang R, Zhou L. Measuring the caregiver burden of caring for community-residing people with Alzheimer's disease. PLoS One. 2015;10(7):e0132168.

53. Fujinami R, Otis-Green S, Klein L, Sidhu R, Ferrell B. Quality of life of family caregivers: challenges faced in care of the lung cancer patient. Clin J Oncol Nurs. 2012;16(6):E210-E220.

54. Toseland RW, Haigler DH, Monahan DJ. Education and Support Programs for Caregivers: Research, Practice, Policy. New York, NY: Springer; 2011.

55. Abdollahpour I, Nedjat S, Noroozian M, Salimi Y, Majdzadeh R. Caregiver burden the strongest predictor of self-rated health in caregivers of patients with dementia. J Geriatr Psychiatry Neurol. 2014;27(3):172-180.

56. Ho SC, Chan A, Woo J, Chong P, Sham A. Impact of caregiving on health and quality of life: a comparative population-based study of caregivers for elderly persons and noncaregivers. J Gerontol A Biol Sci Med Sci. 2009;64:873-879.

57. Maslach C. Burnout: The Cost of Caring. Cambridge: Malor Books; 2003.

58. Garlo K, O’Leary JR, Van Ness PH, Fried TR. Caregiver burden in caregivers of older adults with advanced illness. J Am Geriatr Soc. 2010; 58(12):2315-2322.

59. Perera S, Patel KV, Rosano C, et al. Gait speed predicts incident disability: a pooled analysis. J Gerontol A Biol Sci Med Sci. 2016;71:63-71.

60. Studenski S, Perera S, Patel K, et al. Gait speed and survival in older adults. JAMA. 2011;305:50-58.

61. Bień B, Bień-Barkowska K. Objective drivers of subjective well-being in geriatric inpatients: mobility function and level of education are general predictors of self-evaluated health, feeling of loneliness, and severity of depression symptoms. Quol Life Res. 2016;25(12):3047-3056.

62. Piercy J, Rajagopalan K, Jones E, Pike J. Burden of walking and mobility problems in MS: Analysis of caregiver and indirect costs. Value Health. 2011;14:205.

63. Pike J, Jones E, Rajagopalan K, Piercy J, Anderson P. Social and economic burden of walking and mobility problems in multiple sclerosis. BMC Neurol. 2012;12:94

64. Jansen APD, van Hout HPJ, Nijpels G, et al. Effectiveness of case management among older adults with early symptoms of dementia and their primary informal caregivers: a randomized clinical trial. Int J Nurs Stud. 2011;48(8):933-943.
Clinical Interventions in Aging

\section{Publish your work in this journal}

Clinical Interventions in Aging is an international, peer-reviewed journal focusing on evidence-based reports on the value or lack thereof of treatments intended to prevent or delay the onset of maladaptive correlates of aging in human beings. This journal is indexed on PubMed Central, MedLine,

\section{Dovepress}

CAS, Scopus and the Elsevier Bibliographic databases. The manuscript management system is completely online and includes a very quick and fair peer-review system, which is all easy to use. Visit http://www.dovepress. com/testimonials.php to read real quotes from published authors. 